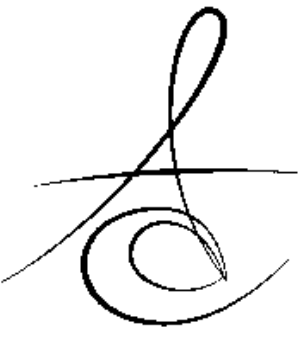

\section{FİZİKSEL ŞİDDETE BAĞLI MANDİBULAR TRAVMA GÖRÜLME SIKLIĞI - 126 HASTA - 7 YILLIK ARAŞTIRMA}

\section{PREVALENCE OF MANDIBULAR TRAUMA RESULTING FROM PHYSICAL VIOLANCE - 126 PATIENTS - A 7-YEAR INVESTIGATION}

\author{
Dr. Öğr. Üyesi. Nazife Begüm KARAN* \\ Dt. Ali GİZLí ${ }^{* *}$
}

Makale Kodu/Article code: 3540

Makale Gönderilme tarihi: 03.01.2018

Kabul Tarihi; 26.06.2018

\section{Öz}

Amaç: Gazi Üniversitesi Diş Hekimliği Fakültesi'ne başvuran hastalarda meydana gelen mandibula kırıklarının etiyolojisinin, önceki çalışmalarla uyum gösterip göstermediğini ortaya koymaktır.

Gereç ve Yöntem: Travma nedeniyle oluşan maksillofasiyal kırık vakaları sıklıkla karşımıza çıkan olgulardır. Maksillofasiyal travmalarda en çok kırılan kemik mandibuladır. Bu çalışmada, 2010-2017 tarihleri arasında fakültemize başvuran ve tıbbi kayıtlarına ulaşılabilen 126 mandibular kırık olgusunun verileri retrospektif olarak incelendi. Yaş, cinsiyet gibi demografik özellikler, etiyolojik faktörler, kırık yeri ve lokalizasyonu, kırık hattında diş mevcudiyeti, tedavi yöntemi, kırık türü, segmentlerde deplasman mevcudiyeti, beraberinde olan yüz yaralanmaları varlığı, komplikasyon görülme sıklığı geriye dönük olarak değerlendirildi.

Bulgular: Toplam 132 hastadan 126'sının verileri bu çalışma için kullanıldı. 7 yıllık süre içerisinde 126 hastada toplam 155 adet kırık teşhis ve tedavi edildi. Erkek/Kadın oranı 2,7:1 olarak bulundu. Hastaların ortalama yaşı 32 olarak hesaplandı. En fazla görülen travma etkeni fiziksel şiddet (\%38.09), en yaygın görülen lokalizasyon mandibula angulus bölgesi (\%21.93) olarak belirlendi. Vakalardan 29 tanesinde çoklu kırık varlığı tespit edildi. 12 vakada (\%9.52) postoperatif enfeksiyon ve 8 vakada (\%6.34) rijit fiksasyon başarısızlığı gözlendi. Kırıkların \%9.52'si açık redüksiyon, \%41.26'sı kapalı redüksiyon ve \%49.20'si açık redüksiyon ve intermaksiller fiksasyon ile tedavi edildi.

Sonuç: Önceki çalışmalarla uyumlu olarak mandibula kırıklarının etiyolojisinde en önemli faktör \%38,09 oranıyla fiziksel şiddet, ardından $\% 24,60$ oranı ile trafik kazaları olarak saptandı.

Anahtar Kelimeler: Mandibula kırıkları; travma; etiyolojik faktörler; fiziksel şiddet

\section{ABSTRACT}

Aim: To demonstrate whether the etiology of mandibular fractures in patients referred to Gazi University Faculty of Dentistry correlates with the results obtained in previous studies.

Materials and Methods: Maxillofacial fractures caused by trauma are frequently encountered cases. In maxillofacial trauma, the most fractured bone is mandible. In this study, retrospective review of the medical records of 126 mandibular fracture cases that referred between 2010-2017 are enrolled and all recorded data were examined. Demographic features such as age and sex, etiology, location of fracture, presence of teeth at fracture line, treatment method, fracture type, presence of displacement in segments, presence of accompanying facial injuries and incidence of complications were recorded and retrospectively evaluated.

Results: The total number of patients was determined as 132 and the data of 126 were used for this study. A total of 155 fractures were diagnosed and treated in 126 patients over a period of 7 years. Male/Female ratio was 2,7:1. The mean age of the patients was 32. The highest etiologic factor of the trauma was interpersonal violance (38.09\%). The most common fractured anatomic site was angle of mandible $(21.93 \%)$. Multiple fractures were detected in 29 cases. The highest complication rate was found to be postoperative infection $9.52 \%$ in 12 cases and rigid fixation failures $6.34 \%$ in 8 cases. Fractures were treated with $9.52 \%$ open reduction, $41.26 \%$ closed reduction and \%49.20 open reduction and intermaxillary fixation.

Conclusion: Consistent with previous studies, the most important etiologic factor in the etiology of mandibular fractures was physical violence with $38,09 \%$, followed by traffic accidents with $24,60 \%$. Keywords: Mandibular fractures; trauma; etiologic factors; bullying

\footnotetext{
* Recep Tayyip Erdoğan Üniversitesi Diş Hekimliği Fakültesi Ağız, Diş ve Çene Cerrahisi Anabilim Dalı ,Rize,

${ }^{* *}$ Gazi Üniversitesi Diş Hekimliği Fakültesi Ağız, Diş ve Çene Cerrahisi Anabilim Dalı, Ankara
} 


\section{GİRİş}

Yüz travmaları, trafik ${ }^{1}$, işs ${ }^{2,3}$ ve spor kazaları ${ }^{4}$ ile fiziksel şiddet ${ }^{5}$ gibi çeşitli nedenlere bağlı olarak gelişirler. Mandibula yüzün en büyük ve güçlü kemiklerinden biri olmasına rağmen, konumu ve çıkıntılı yapısından ötürü nazal kemikten sonra yüz travmalarında en sık kırılan ikinci kemiktir. ${ }^{6,7}$ Bu kırıklar fasiyal yaralanmaların $\%$ 10-25'ini oluşturur. ${ }^{8}$ Mandibula kırıklarının tedavisi halen travmatolojideki en önemli konulardan biridir.

Mandibula kırıklarında teşhis en önemli husustur. Klinik muayenede; mandibula konturunun devamlılığı, oklüzyon, fonksiyon esnasında çene hareketlerindeki değişimler, parestezi mevcudiyeti gözden geçirilmelidir. Kırık hattında diş kayıpları, çevre mukozada laserasyonlar, krepitasyon, hematom ve ekimoz gibi belirti ve semptomlar görülebilir. ${ }^{9-11}$ Klinik muayenenin yanı sıra, radyografik yöntemler de tanı koymada büyük öneme sahiptir. Panoramik radyografiler tüm mandibulayı tek bir alanda inceleme imkanı sağladığından, en çok kullanılan radyografi yöntemi olmuştur. Süperpozisyonlardan şüpheleniliyorsa veya çoklu travma vakalarında detaylı inceleme yapabilmek için, bilgisayarlı tomografi ile görüntüleme ilk tercih olmalıdır. ${ }^{(12,13)}$

Mandibula kırıkları; kırığın lokalizasyonuna, tipine, kasların etkisine, etkenin şekline ve çenelerdeki dentisyonun durumuna göre birçok şekilde sınıflandırılmıştır. Bazı basit travma vakalarında; deplasman oluşmadan, yaş ağaç kırığı şeklinde görülürken, ağır olgularda; deplase, çok parçalı, birleşik, çevre dokuları da içine alacak şekilde gözlenebilir. ${ }^{14}$

Mandibula kırıklarının tedavisinde; estetik ve fonksiyonun tekrar elde edilebilmesi için çeşitli tedavi stratejileri geliştirilmiş ve uygulanmıştır. Gelen travmanın türü ve yönü, kırığın cinsine ve dolayısıyla da kullanılacak tedavi yöntemine etki eder. Maksillofasiyal travma vakalarında vücutta çoklu kırıklar bulunabilir ve hastanın genel durumu stabil olmayabilir. Böyle durumlarda hasta stabil olana kadar mandibula kırığının tedavisi ertelenebilir. Tedavi yöntemleri açık redüksiyon ve kapalı redüksiyon olmak üzere iki şekilde gerçekleştirilir. Konservatif olan kapalı redüksiyon; alt ve üst çenenin doğru oklüzyonda birbirine tel ya da intermaksiller fiksasyon vidaları ile fikse edilmesi şeklindedir. Açık redüksiyonda ise kırığın lokalize olduğu bölge cerrahi olarak açılarak kırık segmentlerin plak ve vidalar aracılığı ile fiksasyonu gerçekleştirilir. Temel amaç; fonksiyon ve estetiği yeniden kazandırmak ve hastayı en kısa sürede sosyal yaşantısına geri döndürmektir.

Literatürde maksillofasiyal kırık vakalarında yapılan tedavi şekilleri, komplikasyonları ve etiyolojik faktörler ile ilgili birçok çalışma mevcuttur. Maksillofasiyal yaralanmaların etiyolojisi yaşam standartlarının değişmesi ile yıllar içerisinde değişmiştir. Bu çalışmada; farklı olarak tüm maksillofasiyal kırık vakaları değil, sadece mandibula kırığı olan vakaların özellikleri incelenmiştir. Çalışmanın amacı; Gazi Üniversitesi Diş Hekimliği Fakültesi'ne başvuran hastalarda meydana gelen mandibula kırıklarının etiyolojisinin, önceki çalışmalarla benzerlik gösterip göstermediğini ortaya koymaktır.

\section{GEREÇ VE YÖNTEM}

Bu çalışmada, Gazi Üniversitesi Ağız Diş ve Çene Cerrahisi bölümü arşivinden, Mart 2010 Temmuz 2017 tarihleri arasında başvuran, 132 maksillofasiyal travma hastası incelendi. Kullanılacak olan veriler için hastalara çalışma öncesinde gerekli bilgiler verilmiş ve ilgili onamlar alındı. 132 hastadan 126'sında mandibula kırığı olduğu saptandı, geri kalanı çalışma dışında bırakıldı. Yaş, cinsiyet gibi demografik özellikler, etiyolojik faktörler, kırık yeri ve lokalizasyonu, kırık hattında diş mevcudiyeti, tedavi yöntemi, kırık türü, segmentlerde oluşan deplasman, ilişkili yüz yaralanması varlığı, komplikasyon gelişimi oranı ve tüm radyografik bilgiler kayıt edildi ve geriye dönük olarak değerlendirildi.

\section{BULGULAR}

Çalışmaya dahil edilen hastaların yaş ve cinsiyet oranları dağılımı Tablo 1'deki gibidir. Hastaların cinsiyet oranı Erkek/Kadın olarak 2,7:1'dir. Gelen kırık hastalarının yaş ortalaması 32'dir (en küçüğü 4, en büyüğü 82 yaşında). (Tablo 1) Araştırmanın sonucunda; en sık görülen etiyolojik sebep fiziksel şiddet ve ardından trafik kazaları, düşme yaralanmaları, iş ve spor kazaları şeklinde sıralandı. (Tablo 2) En yaygın mandibula angulus (\%21.93) ve azan sırayla parasimfiz, kondil, korpus, simfiz, koronoid, ramus, alveol bölgesinde kırıklar izlendi. (Tablo 3) Vakalardan 29'unda çoklu kırık tespit edildi.

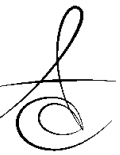


Çoklu kıık varlığı tespit edilen vakalarda en sık parasimfiz ve karşı taraf kondil bölgesinde kırık gözlendi. 88 kırıkta, kırık hattında diş mevcudiyeti saptandı, bu dişlerden 26 tanesinin gömülü olduğu tespit edildi. 12 vakada postoperatif enfeksiyon ve 8 vakada rijit fiksasyon başarısızlığı, komplikasyon sebepleri olarak belirlendi. Kırıkların \% 9.52'si açık redüksiyon, \% 41.26'sı kapalı redüksiyon ve $\% 49.20$ 'si açık redüksiyon ve intermaksiller fiksasyon ile tedavi edildi. (Tablo 4) Çoklu kırıklarda, total dişsiz hastalarda, deplasmanın fazla olduğu durumlarda açık redüksiyon ile fiksasyonun tercih edildiği saptandı. 61 hastada, kırık segmentleri arasında deplasman tespit edildi. En sık basit kırık ve azalan sırayla çok parçalı, birleşik, kompleks, yeşil ağaç ve patolojik kırıklar ile karşılaşıldı. (Tablo 5) Kapalı redüksiyon ile tedavi edilen hastaların intermaksiller fiksasyon süresinin ortalama 4-6 hafta şeklinde olduğu gözlendi. Açık redüksiyon yapılan 64 hastanın 51'inin yatarak, 13 'ünün ayaktan tedavi edildiği saptandı. Sadece kapalı redüksiyon ile tedavi edilen vakaların hepsinin ayaktan tedavi edildiği belirlendi.

Tablo 1. Cinsiyet ve Yaş dağılımı ve yüzdeleri

\begin{tabular}{|l|l|l|}
\hline Cinsiyet & Hasta Sayısı & Yüzde \% \\
\hline Erkek & 92 & $\% 73.01$ \\
\hline Kadın & 34 & $\% 26.98$ \\
\hline Yaş & & \\
\hline $0-9$ & 3 & $\% 2.38$ \\
\hline $10-19$ & 30 & $\% 23.80$ \\
\hline $20-29$ & 25 & $\% 19.84$ \\
\hline $30-39$ & 23 & $\% 18.25$ \\
\hline $40-49$ & 21 & $\% 16.6$ \\
\hline $50-59$ & 15 & $\% 11.90$ \\
\hline $60-69$ & 7 & $\% 5.55$ \\
\hline 70 ve Üzeri & 2 & $\% 1.58$ \\
\hline Toplam Hasta Sayısı & 126 & \\
\hline
\end{tabular}

Tablo 2. Kırık etiyolojisi ve yüzdeleri

\begin{tabular}{|l|l|l|}
\hline ETİYOLOJİ & $\begin{array}{l}\text { HASTA } \\
\text { SAYISI }\end{array}$ & YÜZDE \% \\
\hline Fiziksel Şiddet & 48 & $\% 38.09$ \\
\hline Trafik Kazası & 31 & $\% 24.60$ \\
\hline Düşme & 28 & $\% 22.22$ \\
\hline İ Kazası & 10 & $\% 7.93$ \\
\hline Spor Kazaları & 9 & $\% 7.14$ \\
\hline
\end{tabular}

Tablo 3. Mandibular kırıkların bölgelere göre dağıımı ve yüzdeleri

\begin{tabular}{|l|l|l|}
\hline Kırık Bölgesi & Kırık sayısı & Yüzde \% \\
\hline Angulus & 34 & $\% 21.93$ \\
\hline Parasimfiz & 28 & $\% 18.06$ \\
\hline Kondil & 26 & $\% 16.77$ \\
\hline Korpus & 23 & $\% 14.83$ \\
\hline Simfiz & 16 & $\% 10.32$ \\
\hline Koronoid & 11 & $\% 7.09$ \\
\hline Ramus & 9 & $\% 5.80$ \\
\hline Alveol & 8 & $\% 5.16$ \\
\hline Toplam Kırık Sayısı & 155 & \\
\hline
\end{tabular}

Tablo 4 . Uygulanan tedavi yöntemleri ve yüzdeleri

\begin{tabular}{|l|l|l|}
\hline $\begin{array}{l}\text { Uygulanan Tedavi } \\
\text { Yöntemi }\end{array}$ & $\begin{array}{l}\text { Hasta } \\
\text { Sayısı }\end{array}$ & Yüzde \% \\
\hline Açık Redüksiyon & 12 & $\% 9.52$ \\
\hline $\begin{array}{l}\text { Açık Redüksiyon ve } \\
\text { İntermaksiller Fiksasyon }\end{array}$ & 52 & $\% 41.26$ \\
\hline $\begin{array}{l}\text { Kapalı Redüksiyon ve } \\
\text { İntermaksiller Fiksasyon }\end{array}$ & 62 & $\% 49.20$ \\
\hline
\end{tabular}

\section{TARTIŞMA}

Maksillofasiyal travmanın etiyolojisi zamana ve bölgeye göre değişiklik göstermektedir. Bu çalışmada, en çok fiziksel şiddetin ve ardından sırayla trafik kazaları, düşme, spor yaralanmaları ve iş kazalarının mandibular kırıklara sebep olduğu belirlendi.

Ülkemizde ve diğer ülkelerde, sıralamada değişiklikler olsa da etiyolojik nedenler neredeyse hiç değişmemektedir. İzmir Atatürk Eğitim ve Araştırma Hastanesi Plastik Rekonstrüktif ve Estetik Cerrahi bölümünde 2006-2007 yıllarında, 124 vakada \% 41.9 oranıyla, en çok fiziksel şiddet kaynaklı kırık oluşumu saptanmıştır. ${ }^{(15)}$ Osmangazi Üniversitesi Tıp Fakültesi Plastik Rekonstrüktif ve Estetik Cerrahi bölümünde, 1998-2007 yılları arasında 232 vaka üzerinde yapılan bir çalışmada da mandibula kırıklarının ilk sırada yer aldığı teyit edilmiş ancak en sık karşılaşılan etiyolojik faktörün trafik kazaları olduğu bildirilmiştir. ${ }^{16}$

Türkiye'de yapılan araştırmalarda maksillofasiyal bölge kırıklarının genellikle 20-30 yaş arasındaki erkek hasta popülasyonunda görüldüğü tespit edilmiştir. Yurt dışında yayınlanan çalışmalarda yine aynı sonuçlar elde edilmiş; ancak, darp ya da fiziksel

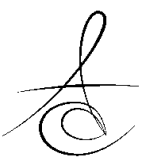


şiddet nedenli kırık görülme sıklığı daha alt sıralarda yer almıştır. ${ }^{15}$ Şimdiki çalışmanın sonucunda, mandibular travma en sık 10-20 yaş grubunda izlense de onu hemen alt sırada 20-30 yaş grubu takip etmektedir. Travmanın etiyolojik faktörlerindeki bu değişimin toplumsal eğitim ve sosyokültürel refah seviyesine bağıı olduğu düşünülebilir.

Brezilya'da 2017 yılında yapılan 10 yıllık bir araştırmaya göre yine fiziksel şiddete bağlı meydana gelen maksillofasiyal travma olgularının çok yüksek olduğu ve trafik kazaları ile neredeyse aynı oranda rapor edildiği saptanmıştır. Travma nedenlerinin, genç erkek erişkinlerde şiddete, ilerlemiş yaştaki kadınlarda ise düşmeye bağlı olduğu rapor edilmiştir. ${ }^{17}$ Maksillofasiyal bölge travmalarını inceleyen, İran'da 2017'de yapılan bir çalışmada en sık motorlu araç kullanımına bağlı travma gözlenmiş ve bunu fiziksel şiddetin izlediği rapor edilmiştir. ${ }^{18}$ Çalışmalardaki farklılıkların nedeni; çalışmanın yapıldığı bölge, popülasyon ve zaman periyodunun farklı olmasına bağlanabilir.

Spor yaralanmalarında maksillofasiyal bölgede en çok mandibular kemikte kırık meydana gelmektedir. Her ne kadar spor faaliyetlerinde oluşan yaralanmaların, kasket, gözlük gibi koruyucu ekipmanların kullanımı ile geçmişe oranla azaldığı bilinse de, yeni spor akımlarının yükselmesi ve daha zorlayıcı ve tehlikeli sporların ortaya çıkması ile son yıllarda spor kazalarına bağlı bildirilen mandibula kırıkları da artmıştır. $^{19}$

Literatürde yer alan bilgilere göre mandibular kırıkların en fazla görüldüğü yer parasimfiz bölgesi olarak bildirilmiştir. ${ }^{15-18}$ Şimdiki çalışmada ilk sırada angulus kırıkları yer almasına rağmen parasimfiz kırıklarının ikinci sırada yer aldığı izlenmektedir.

Mevcut çalışmada, mandibula kırıklarınn etiyolojisindeki en önemli faktör \%38,09 oranıyla fiziksel şiddet olarak saptanmış ve bunu \%24,60 oranı ile trafik kazaları takip etmiştir. Erkeklerde gözlenen travma sıklığının kadınlara oranla en az iki kat fazla olması, incelenen diğer çalışmalarla uyum göstermektedir. Türkiye'de şiddete eğilimin artmasıyla, trafik kazası kaynaklı travma olgularının ikinci sıraya indiği düşünülmüştür. Nitekim, Türkiye İstatistik Kurumu (TUİK)'nun 2017 yılı verilerine göre ölümlerin (18.901) \%4,5'i (en sık altıncı ölüm nedeni) dışsal yaralanma sonucu gerçekleşmiştir. ${ }^{20}$ Ayrıca trafik kontrol ve denetimlerinin sıkılaştırılması, emniyet kemeri

kullanımının artması, trafik kazalarına bağlı olarak gelişen toplam ölüm vakalarındaki düşüşün nedeni olabilir. $^{21}$

Mandibula kırıklarının tedavisinde altın standartın, intermaksiller fiksasyon (IMF) eşliğinde yapılan açık redüksiyon olduğu savunulmaktadır. Ancak buna rağmen; tedaviyi üstlenen doktorun seçimi, hastanın uyumu ve göreceli komplikasyon riskleri açısından en sık tercih edilen yöntemin IMF eşliğinde yapılan kapalı tedavi olduğu bildirilmiştir. ${ }^{22}$ Nitekim, bu çalışma sonucunda da hastaların daha çok IMF eşliğinde kapalı redüksiyonla tedavi edildiği ortaya çıkmıştır.

Sonuç olarak; maksillofasiyal yaralanmalarda mandibula kırıkları en sık karşımıza çıkan kırıklardır. Tedavilerine ne kadar erken başlanırsa o kadar başarılı sonuçlar alınır ve oluşabilecek komplikasyonlar en aza indirgenir. ${ }^{23}$ Tedavi yöntemi olarak hangi yöntem uygulanırsa uygulansın temel amaç; hastaya önceki fonksiyon ve estetiğini yeniden kazandırmak ve en kısa sürede sosyal yaşantısına geri döndürmektir. Bu çalışmada, fiziksel şiddetin mandibular kırık oluşumunda birincil etken olduğu ve daha çok erkeklerde gözlendiği ortaya çıkmıştır. Toplumsal bilincin, eğitimin ve halkın refah seviyesinin arttırılmasıyla, şiddetin önüne geçilerek, travma vakalarında azalmanın sağlanabileceği görüşüne varılmıştır.

Nazife Begüm Karan: ORCID ID: 0000-0003-1027-792X Hüseyin Ozan Akıncl: ORCID ID: 0000-0002-7953-3189 Ali Gizli: ORCID ID: 0000-0002-6165-5954

Ziver Ergun Yücel: ORCID ID: 0000-0001-7161-6433

\section{KAYNAKLAR}

1. Aladelusi TO, Akinmoladun IV, Olusanya OO, Akadiri OA, Fasola AO. Evaluation of pedestrian road traffic maxillofacial injuries in a Nigerian tertiary hospital. Afr J Med Med Sci 2014;43:3539.

2. Yamamoto $K$, Matsusue $Y$, Murakami $K$, Horita S, Matsubara $Y$, Sugiura T, Kirita T. Maxillofacial fractures due to work-related accidents. J Craniomaxillofac Surg 2011;39:182-6.

3. Hachl O, Tuli T, Schwabegger A, Gassner R. Maxillofacial trauma due to work-related accidents. Int J Oral Maxillofac Surg 2002;31:903. 
4. Yamamoto K, Matsusue $Y$, Horita S, Murakami K, Sugiura T, Kirita T. Maxillofacial fractures sustained in bicycle accidents. J Oral Maxillofac Surg 2011;69:155-60.

5. Ferreira MC, Batista AM, Ferreira Fde O, RamosJorge ML, Marques LS. Pattern of oralmaxillofacial trauma stemming from interpersonal physical violence and determinant factors. Dent Traumatol 2014;30:15-21.

6. Nogami S, Yamauchi K, Yamashita T, Kataoka $Y$, Hirayama B, Tanaka K, Takahashi T. Elderly patients with maxillofacial trauma: study of mandibular condyle fractures. Dent Traumatol 2015;31:73-6.

7. Busuito MJ, Smith DJ, Jr., Robson MC. Mandibular fractures in an urban trauma center. J Trauma 1986;26:826-9.

8. Lipski M, Pelka P, Majewski S, Lipska W, Gladysz T, Tomaszewska I. Mandible - clinically revisited. Folia Med Cracov 2013;53:29-35.

9. Fonseca RJ, Barber HD, Powers MP, Frost DE. Oral and Maxillofac Trauma. E-Book: Elsevier Health Sciences 2013. p. 302.

10. Peterson L, Ellis E, Hupp JR, Tucker MR(ed). Contemporary oral and maxillofacial surgery. J Oral Maxillofac Surg 3 ed. St Louis; MO; 1999. p. 492.

11. Ghali GE, Larsen P, Waite P, Miloro M(ed). Peterson's Principles of Oral and Maxillofacial Surgery: B C Decker. 2 ed. PMPH-USA; 2004. p. 1485.

12. Schubert W. Radiographic diagnosis of mandibular fractures: Mode and implications. Oper Tech Otolaryngol Head Neck Surg 2002;13:246-53.

13. Chayra GA, Meador LR, Laskin DM. Comparison of panoramic and standard radiographs for the diagnosis of mandibular fractures. J Oral Maxillofac Surg 1986;44:677-9.

14. Türker M, Yücetaş Ş. Ağız Diş Çene Hastalıkları ve Cerrahisi 3. ed. Ankara; Özyurt Matbaacillk İnş. Taah San Ve Tic Ltd Şti: 2004. p. 559-608.

15. Demirdöver C, Şahin B, Ataseven M, Özkan HS, Öztan HY.Bir yll içinde opere edilen 124 mandibula fraktürü olgusunun geriye dönük incelenmesi.Turk J Plast Surg 2010;17:145-8.
16. Şakrak T, Köse A, Karabağlı Y, Elmas İ, Tekgöz A, Çetin C. 232 Maksillofasyal travmalı hastanın geriye dönük analizi ve kliniğimizde uygulanan tedavi protokolleri. Turk J Plast Surg 2011;18:669.

17. Possebon APR, Granke $G$, Faot $F$, Pinto LR, Leite FRM, Torriani MA. Etiology, diagnosis, and demographic analysis of maxillofacial trauma in elderly persons: A 10-year investigation. J Craniomaxillofac Surg 2017;45:1921-6.

18. Rezaei $M$, Jamshidi $S$, Jalilian $T$, Falahi $N$. Epidemiology of maxillofacial trauma in a university hospital of Kermanshah, Iran. J Oral Maxillofac Surg Med Pathol 2017;29:110-5.

19. Viozzi CF. Maxillofacial and Mandibular Fractures in Sports. Clin Sports Med 2017;36:355-68.

20. Ölüm nedeni istatistikleri, 2017. T.C. Türkiye İstatistik Kurumu Başkanlığı (TÜİK). file://C:/Users/DH5/Downloads/\%C3\%961\%C3 \%BCm_Nedeni_\%C4\%BOstatistikleri_26.04.2018 .pdf

21. Karayolu Trafik Kaza İstatistikleri, 2016-2017. Türkiye İstatistik Kurumu Başkanlığı (TÜİK). www.tuik.gov.tr/PdfGetir.do?id=24606

22. Malik S, Singh G, Kaur G, Yadav S, Mittal HC. Orofacial trauma in rural India: A clinical study. Chin J Traumatol 2017;20:216-21.

23. Kuvvetli SS, Sandallı N. Çocuklarda ve genç erişkinlerde temporomandibular rahatsızlıklar: Literatür derlemesi. Atatürk Üniv Dis Hek Fak Derg 2007:2:1-9.

\section{Yazışma Adresi}

Dr. Öğr. Üyesi Nazife Begüm KARAN

Recep Tayyip Erdoğan Üniversitesi

Diş Hekimliği Fakültesi

Ağız, Diş ve Çene Cerrahisi Anabilim Dalı

Rize,TÜRKIYYE.

Tel: +90 (464) 2220002

E-mail: karanbegum@gmail.com 